\title{
Research on the Systematic Humanity Education
}

\section{and the Countermeasures}

\author{
Liying Shen \& Guoyong Xie \\ Dezhou University \\ Dezhou 253000, China \\ E-mail: dzxgy8069@163.com
}

\begin{abstract}
Humanity education is a large systematic project, in which we should not only pay attention to the joint efforts of all aspects, but also the cohesion of all aspects. This thesis findsthe existing problems in the humanity education from the aspects of community, schools and parents and then the countermeasures and technical strategies are discussed to solve these problems.
\end{abstract}

Keywords: Humanity education, Existing problems, Countermeasures

Humanism originates from Europe. Contrary to the doctrine of deity-centered, humanism puts human at the center. At the beginning, it was just a more advanced thought, and then gradually evolved into a worldview and a moral philosophy. Humanism is any system or mode of thought or action in which human interests, values, and dignity predominate and it is a variety of ethical theory and practice that emphasizes reason, scientific inquiry, and human fulfillment in the natural world and often rejects the importance of belief in god.

With the development of reform, the issue on the individual "human being" is drawing more and more attention in present China. Especially in recent years, "people-oriented" is being promoted everywhere. It seems to be a good social phenomenon, but the goal of being a people-oriented society is far from being reached.Most often the reason for this is that humanism is not yet deeply understood and researched. Therefore, we need to attach much importance to all aspects of humanity education so that it can be routine and systematic. Only in this way, can "people-oriented" be a worldview and a social value.

There are varieties of references on the meaning of humanities education, and three of the most common ones are as follows: the first is the humanistic education, the second ishumanities education and the third is on the "adulteducation". This thesis is rather tendentious on the third one.

Comenius pointed out long ago that to from a person should be by means of the education. With regard to "adult education", the minimum requirement is to educate people so that they can get certain knowledge; the higher demand is to make people more complete, which means the full development of people from the aspects of morality, intelligence and physics and the highest demand is to make people perfect. Therefore, the fundamental aim of humanity education is to promote the human realm of the educated and to shape their ideal personalities as well as the implementation of the personal and social values. The core of humanity education is to enrich the human spirit rather than just stay in the access to relevant human knowledge.

For a long time, there is a misunderstanding on the humanity education, which holds the idea that humanity education is just that humanities education. Undoubtedly, humanistic education is an important aspect of education, but not all. Strengthening humanity education should be something to the whole society, not just to the schools, and humanity education should be something to all aspects, not just one side of it. Therefore, humanity education is a systematic project.

\section{Existing problems in the humanity education}

Nowadays in China, there are many problems existing in the humanity education.

From a social point of view, "people-oriented" is strong advocated everywhere, but how to fulfill lacks specific measures and channels. The government strongly advocates "people-oriented", while certain inhuman phenomenon occurs, such as "fishing event" and "house crunchy events". Many Mediaspromote truth-seeking, moral-establishing and artistry in life, but for the economic profits and utilitarian target, they keep producing so-called gimmick to mislead the young people and the audience. As a member of society, he wants to be 
respected, but when his own interests are at stake, he chooses to escape and deserts morality, and even selects treachery.

From the perspective of school, many managers know what human-management is and what student-centered is. But they know little as to how tocarry out humanity education to the students. Therefore, humanity education can not arouse manager's attention and awareness. And thus instant benefits emerges from the place of education, such as the unfair competition in the enrollment and school size, even academic fraud. Correspondingly, the teachers also have no sense of humanity education. They pay little attention to their own self-improvement and they seldom give students human care. All these things have great impact on the students, especially those minors.

From the perspective of family, many parentsdo not know what humanity education is and they have never heard of it. What they do is to simply follow their own logic and ideas to educate their children. Some parents only teach their children what should do, but they do not take into account what is wrong with their own behaviors. And there are parents who only care about creating a comfortable physical environment for their children, but ignoring the companionship and spiritual communication. However, there are parents who want to communicate with their children and want them to be sensible, but they do not know what the right ways and means to use. Consequently, both parents and students are not satisfied.

As to the existing problems which have been mentioned above, we further recognize that humanity education is not only important, but also it is a systematic project. It is not enough to depend upon one's effort only.

\section{Strategiesto strengthen humanity education}

First, it is necessary to realize that humanity education is a systematic project. Therefore, the government and the education authority need to mobilize all forces to lead the community to attach much importance to humanity education. The first step is to advocate sound social moralities, such as helpfulness, to respect teachers and attach importance to education and to respect the aged and love the young. In other words, what we should do is to strongly promote the goodness and whip the ugly social phenomena. The second step is to work out ethical rules suitable to Chinese conditions and these ethical rules are ought to be taught to children. We should have a strong sense of realizing it and start it from the smallest things. Thirdly, the study of Chinese classical culture and history should be strongly advocated so that the essence of Chinese culture can be inherited by later generations. The last step is to gradually abandon examination-oriented education and strengthen quality education. It is important to train more qualified personnel for society.

Then, we should pay attention to the various stages and levels of education and their interface. At the same time, each school should create a humanity atmosphere. School is a place specifically for education. The formation of people's outlook on life is closely related to school education. Therefore, education plays an important part in children's growing up. At present, education at all stages has realized the knowledge link and the interface between diplomats. However, it is messy without law as tohow to conduct oneself in society and adult education. In order to change this situation and fully display school's role in adult education, humanity education in school should be both routine and systematic. Therefore, the first step is to put emphasis on humanity curriculum. The establishment of humanity courses should be from early childhood to university education, in which history, literature and philosophy should be the core subjects. Secondly, attention should be paid to the contents of humanity textbooks. It is necessary to make sure the contents proceed from simple ones to more complicate ones, so that students from different levels can learn them more easily and be affected more and more. The third step is to establish specialized courses on humanity in universities and train expertise in humanistic education for different levels ofschools, and thus the quality of humanity education can be improved in each school. It is understood that humanity education has just opened for a few years. There are over thirty universities to establish courses in humanity and most of them are second or third class universities, which can not meet the national needs. The fourth step is to enhance the training of teachers and to help teachers to foster their awareness of humanistic education. Besides, in the process of teaching, teachers are required to take students' actual performance into account and then combine some content of humanity education with the teaching materials. Meanwhile, teachers need to improve their personal charm. They are not only knowledgeable but also they should understand their students and care about them, and then teachers' humanity quality can be ultimately improved. Fifthly, it is important to improve the assessment system. Students' evaluation on their teachers should be regarded as a core index. The standards of teachers' assessment include students' achievement evaluation. In addition, whether the teachers possess vast knowledge, whether they can attach much importance to educate students and whether they can meet students' need are also taken into consideration to evaluate teachers. Only in this way, can teachers be encouraged to engage in scholarship and they can educate their students more 
efficiently. And then, there will be more and more excellent inspiring teachers. Sixth, there should be a humanity atmosphere in schools. Both hardware facilities and professional faculty forces should be paid equal attention in construction of schools. Teachers and administrators should improve their humanity qualities and give students more humanistic care, so that students can learn and acquire imperceptibly virtuous qualities of human behaviors in a loving environment. Meanwhile, it is useful to carry out some communities activities and fully stimulate students' initiative, so that the potential of each student can be stimulated and developed. And then they develop their abilities and learn how to communicate and cooperate with others. In addition to this, each school should establish its own campus culture and enhance the construction of the campus environment. Posters, billboards and motto, which are about humanity education, can be spread all over campus. In the environment full of humanistic care, students are more likely to establish good human relationships and more likely to learn to love the collective, respect their teachers and care about others. Finally, we must strengthen the necessary connection between schools and parents, especially kindergarden and primary and secondary schools. Therefore, it is necessary for schools to set up a system so that parents can be contacted regularly. As to some students who have problems, schools should immediately get in touch with their parents and exchange their information. And then they can help students to find the cause of their problems. Furthermore, the mutual interaction between schools and parents can be achieved, which is good for the minors' growing up.

All in all, humanity education is large systematic project. Only when the community, families and schools work together, when they set up the awareness of humanity education, can a sound humanistic atmosphere be formed in the whole society, and then more and more talented persons can be trained.

\section{References}

D, Y.H. (2007). Reconstruction of classroom teaching modes in context of humanist education. Journal of Modern Education Science.

Jiang, Y.H. (2002). The core concept of education. The Journal of Jiangsu University.

Li, P. G. (2007). The historical change of the relationship between western scientific education and humanity education. Journal of Hebei Normal University.

Pang, X.G. (1993). The un-ignorance of the other half of education-the modern revival of humanity education and enlightenment.The Journal of Education Research and Experiment.

$\mathrm{Xu}, \mathrm{ZH}$. F. (2003). Study on the issue of "humanity care" from the value of Marxist concept. The Journal of Philosophy Research.

Zhang, Q. L. (2007). The introduction of the spirit of science education in humanity education. Chinese Education Press, 6 June. 